who was there while the epidemic was raging in Aleppo told me that the inhabitants believed that they owed the immunity which they had enjoyed to the purity of their drinking water. The same explanation is probably true in regard to the unexpected escape, in 1883, of Beyrout, whose water-supply is from the Dog river, conveyed in iron pipes to a distance of about eight miles. Cholera was then in Egypt, and more than 200 refugees came over and were put into quarantine. There were three cases of death from undoubted cholera among them, and a sentry at the lazaret, and two washerwomen, who washed their clothes, died soon after. Beyrout was pronounced officially to be infected, and was put into quarantine; but, to the amazement of everyone, there was no further extension of the disease. Beyrout.

\section{PERSONAL OBSERVATIONS OF THE COURSE OF INFLUENZA AND OF CHOLERA IN ASIA DURING THE RECENT EPIDEMICS OF THESE DISEASES.}

BY BENJAMIN HOWARD, M.A., M.D., F.R.C.S.E.

THE following contribution to the history of recent epidemics as observed by me in Asia may be deemed worthy of a place in THE LANCET.

On leaving London in the autumn of 1889 for a prolonged detour in India and other parts of Asia, influenza was in the metropolis becoming the prevalent complaint. During November and December $I$ encountered it in Naples and in Florence - the event most conspicuous in my mind in connexion with this epidemic in Italy being the death of Browning, the poet, who from a bronchitis following this disease died in Venice a few days after my arrival in that city. At Brindisi I took a steamer which had come direct from London. On board this steamer was a gentleman who landed with us in Bombay, still suffering from a severe and prolonged attack of influenza. As this was the only case on board, it became quite a subject of speculation whether or no he might not inoculate Bombay with his influenza. In Bombay, within six weeks, and before I left the hotel we were both staying at, influenza was common amongst the many regular residents of that hotel, and soon after appeared among the villa residents on the neighbouring suburban hills. From India there are three passenger steamship lines running to the healthy little port of Kohe, in Japan. After spending the following summer in the Okotsk Sea and Eastern Siberia, I returned in the end of autumn to Kohe, and immediately was myself attacked with influenza, with which about 30 per cent. of the inhabitants were confined to their houses, and many to their beds. From Kohe to Yokohama, the furthest eastern port, is a run of about thirty-six hours. Here nearly every house, European as well as Japanese, has been invaded by influenza, and of so severe a type that during my stay here many Europeans have died from it, many of the victims being men comparatively young, and of such robust habit that, from the ignoring of the disease, they invited the relapse which proved fatal. The only difference between the disease as it appeared in Japan and as $I$ saw it both in London and India, is that in Japan the constitutional depression has been much greater, several weeks'confinement to bed having been not unusual.

Now for the cholera, which we know has been so severe throughout the greater part of the Japanese Empire the past year. In Bombay during the latter part of the winter of last year there was amongst the general public certainly not a thought about cholera. I was the more assiduous, therefore, to test the statement made to me by several medical officers to the effect that in the Bombay Presidency that disease is rarely or never totally absent. I was at last rewarded by finding a case in the city of Bombay. There had been rice-water discharges and cramps, and the identification of the disease had been endorsed by the removal of the patient to the cholera section of the General Hospital where I found it. I have spoken of the direct lines of mail steamers running from India to the various ports of Japan, Nagasaki, Kohe, \&c., having their terminus at Yokohama. The July following cholera was reported to be at the first of these ports of call, Nagasaki. To this place I went, where the reputed four or five cases I found by actual inspection to mean forty-five cases. Being myself en route for Siberia and a summer cruise in the Okotsk Sea, I took first the mail steamer route, the only line in direct commu. nication with the eastern ports of Corea. Of these ports, Fusan and Jinsan, it was difficult to say which was the filthier, but both of them surpassed in this respect the dirtiest city I had seen even in China. One could not avoid the apprehension that, should cholera break out in either of these places, the whole population must be swept away by it. At Vladivostock, the first Russian port, and the terminus of this only line in direct communication with Japan, there appeared to be at first sight fairly good sanitary conditions. I soon found, however, that, although the situation is particularly good, all the water used is surface water, and this has to be paid for at so much a bucket, as every where in Siberia. Sewerage there is none. On the very next trip of this same steamer from Nagasaki, one of the passengers died of cholera, and the fire was lighted all along its route, including Vladivostock. Of Japan alone is it possible to give even proximate statistics; but, strange as it may seem, in Fusan and Jinsanthe Corean ports, where the corner of every street is an open and overflowing privy - the mortality has not been reported as astonishing. At the northerly Siberian port of Vladivostock the mortality was as great as in Japan, but the cases were comparatively few. In Japan, from July to Dec. 31st last, the total of reported cases was 45,034 ; deaths, 31,484 , giving a mortality of over 69 per cent.

These travelling companionships I hope I have been in no way responsible for, but the coincidences mentioned have been interesting, and, as contributions to the history of these epidemics, may be deemed worth recording.

Yokohama, Japan.

\section{HERNIOTOMY, OR ABDOMINAL SECTION?}

\section{BY HARRY LUPTON, L.R.C.P.LOND., M.R.C.S.ENG.,} SURGEON TO THE STRATFORD-ON-AVON HOSPITAL.

I AM anxious to place on record the following two cases, and shall be only too pleased if their narration leads to the expression of opinions more authoritative than my own. My own bias is, and yet not strongly, to the abdominal method. I must let the cases speak for themselves.

On Sept. 28th, 1890, my friend, Mr. Fenton of Kineton, sent to me Mrs. B-, aged fifty-three, with a history of obstruction ; no hernia could be detected at the usual seats ; but her symptoms becoming so urgent that he considered abdominal section offered the only chance of recovery, she was admitted to the Stratford-on-Avon Hospital, and at once seen by the staff in general consultation. We could add nothing to Mr. Fenton's history of the case; and, as it was evident if the patient was not relieved she had only a few hours to live, it was agreed that I should at once open the abdomen, and endeavour to relieve the obstruction. This I did, and found a very small piece of small intestine, perhaps a third or a half of its circumference, nipped tightly in the right femoral ring. I withdrew it with very little difficulty, and found it dark but distinctly reducible, and returned it. Every precaution as to cleanliness was adopted, but no spray. The wound was dressed simply with absorbent wool. The operation was just done in time. For a time she looked almost like dying on the table; but the pulse improved with the withdrawal of the intestine from the ring, and half an hour after the completion of the dressings she was able to be removed from the table back to her ward. For the rest there is nothing to write abouv. Her symptoms were relieved, and she simply went on getting better. She was discharged cured on Oct. 28th, and has since been busy in her dairy. "Look on that picture and," alas! "on this."

Mrs. G-, aged fifty-seven, was admitted to the Stratfordon-Avon Hospital on Dec. lst, 1890, suffering from strangulated femoral hernia. Her symptoms were urgent, and a consultation of the full staff agreed that immediate operation was necessary. When the patient was under chloroform, one of my colleagues, remembering the excellent result obtained in the case of Mrs. B-, said, "How are you going to operate, Lupton?" The same question was strongly at the moment present in my mind. I had been deeply impressed by the result of the former case, and was 